\title{
Role of diffusion MR imaging (DWI) and three-dimensional ultrasound (3DUS) in the assessment of placental insufficiency in the gestational hypertension
}

Sahar Mansour ${ }^{1 *}$, Soha Hamed ${ }^{1}$, Safia Sayed ${ }^{1}$ and Shreen Hosny ${ }^{2}$

\begin{abstract}
Background: DWI is a non-invasive MR modality that is not contrast-based. In the current study, we aimed to evaluate DWI in correlation with 3DUS in the detection of placental insufficiency in high-risk pregnancies complicated with hypertension.

This prospective analysis included 80 pregnancies; 40 hypertensive and 40 controls, gestational age ranged from 22 to 34 weeks. All cases had undergone 3DUS aided by power Doppler scanning and DWI. There is no given contrast. Data were correlated to histopathology.

Results: Doppler US showed a significant relation between RI of the right uterine artery of cases and control $(P=0.014)$. There was also a positive correlation between the presence of the diastolic notch and RI value. The mean ADC value in the controls was $1.87 \pm 0.26 \mathrm{~mm} 2 / \mathrm{s}$, while in hypertensive was $1.36 \pm 0.09 \mathrm{~mm}^{2} / \mathrm{s}$. In DWI images, there was a significant difference between patients with normal and those with abnormal placental signals ( $P$ value $=0.047$ ). Also, there was a significant difference between the measurement of placental volume by MRI and US among cases and controls ( $P$ values $\leq 0.001$ and 0.017 , respectively).

Conclusion: Diffusion-weighted imaging can detect early subtle findings and signs of placental dysfunction more than detected with 3DUS, so it can add to the diagnostic accuracy of US in imaging of pregnancies at high risk of placental insufficiency.
\end{abstract}

Keywords: Placental abnormalities, Gestational hypertension, 3D power/color Doppler ultrasound, Diffusionweighted MRI, Functional MRI

\section{Background}

Placental insufficiency is a process that causes a progressive deterioration in the placental function and may cause preeclampsia in hypertensive pregnant females [1]. Preeclampsia is a major contributor to maternal mortality and a leading cause of perinatal mortality and morbidity [2].

Ultrasound is the first choice modality in the case of placental evaluation [3]. With the aid of three-dimensional 3D ultrasound, it became accessible to calculate the placental volume [4].

\footnotetext{
*Correspondence: sahar_mnsr@yahoo.com

${ }^{1}$ Radiology Department (Women's Imaging Unit), Faculty of Medicine, Kasr

ElAiny Hospital, Cairo University, Cairo, Egypt

Full list of author information is available at the end of the article
}

Pregnancies with increased vascular impedance on the placental, fetal, and maternal sides can be detected by Doppler examinations of both uterine and the umbilical arteries [5].

The multi-planar capabilities and the improved tissue contrast presented by magnetic resonance (MR) imaging make it a considerable imaging modality for the assessment of the placenta [3]. Also, fast MR sequences allow accurate volumetry of the uteroplacental unit [6].

Diffusion-weighted MR imaging is a non-invasive modality as the ultrasound; moreover, unlike ultrasound, it is a non-operator dependent that provides a wide field of view and multiplanar soft tissue discrimination. 
The current work is a pioneer investigation using 3D ultrasound in correlation with MR imaging in the assessment of placental insufficiency not just regarding ischemic changes but also in view of the whole placental volume.

So we aimed by this work to find out if diffusionweighted imaging can replace/add to the 3D pelvis ultrasound and Doppler in the diagnosis of placental insufficiency in high-risk pregnancies complicated with hypertension.

\section{Methods}

The study is a prospective randomized study that was reviewed by the ethics committee of the Obstetrics and Gynecology and the Radiology Departments and was approved by the review board that is related to our university. Patients included gave informed consent to use their data in research work.

The sample size included 80 cases:

a) Control sample $(n=40)$ was free from any medical disorder by history and clinical examination.

b) Inclusion criteria for the included patients $(n=40)$ : Pregnant patients were at high risk for placental insufficiency regarding their clinical history of either one or all of the following: (1) History of gestational hypertension (i.e., two consecutive reading of high blood pressure of $140 / 90 \mathrm{mmHg}$ or more taken at least $6 \mathrm{~h}$ apart and was continued for more than 4 days in beyond 20 weeks pregnancy), (2) previous history of preeclampsia, (3) previous history of recurrent abortions, and (4) previous history of intra-uterine fetal death (IUFD) and placental abruption.

Exclusion criteria:

a) Diagnosed cases of preeclampsia (i.e., cases confirmed of gestational hypertension and established proteinuria beyond 22 weeks of pregnancy.

b) Contraindication to perform MR imaging as implanted otologic devices with strong magnetic property, cochlear implants... etc.

Both groups (control and cases) were examined between 22 and 34 weeks of gestation. They were referred from the Obstetrics and Gynecology Department, after being examined by 3D ultrasound to the Radiology Department to do the MR imaging studies in the duration from January 2016 to May 2018 with time interval between both examinations \pm 7 days.

We used an ultrasound machine equipped with a 5.0-7.0-MHz transabdominal probe and a combination of
3D and power/color Doppler technology (Voluson Pro 700 General Electric, New York City, USA).

Ultrasound was performed by experienced radiologist and obstetrician of 25 years and 15 years of experience, respectively.

All included patients were examined by the following:

a) Ultrasound

- Routine two-dimensional (2D) ultrasound

- Three-dimensional (3D) power/color Doppler for velocimetry of the (i) umbilical artery (RI and PI) and (ii) uterine artery (mean of both uterine RI and PI)

- Placental volume $\left(\mathrm{cm}^{3}\right)$ was assessed using a 3D "virtual organ computer-aided analysis" (VOCAL) imaging technique.

b) MR imaging

Non-contrast-based MR imaging was performed to detect early signs of placental insufficiency and consequently confirms or excludes preeclampsia in the included cases.

The used MR machine was (1.5 Tesla magnet) Philips scanners (Achieva and Intera, Amsterdam, Netherland) at the Radiology Department.

The patient scanned in the supine position using a pelvic phased-array "Torso" coil.

The maternal pelvis was scanned using the following protocol:

a) T2-weighted pulse sequence spin-echo (SE): TE 80 $\mathrm{ms}$, TR $489 \mathrm{~s}$ in the axial, sagittal, and coronal planes using matrix $256 \times 192$ and flip angle $=90$.

b) Spoiled gradient (T1-TFE): TE $5 \mathrm{~ms}$, TR $15 \mathrm{~ms}$, flip angle $=15$ in the axial plane.

Sequences (1) and (2) were performed with respiratory triggering to control maternal and fetal motion artifacts.

c) Diffusion-weighted MR imaging (DWI), which was scanned with no need to hold breath and $b$ values used were 500, 700, and $850 \mathrm{~s} / \mathrm{mm}^{2}$. Diffusionweighted images were acquired in sagittal and transverse planes in three gradient-encoding directions sufficient to estimate the trace of the average diffusivity.

Post processing ADC maps were performed, and ADC values were automatically calculated by drawing region of interest (ROI) on the areas seen in the placenta of abnormal signal (i.e., the persistent bright signal on the DWI). ADC value was usually expressed in $\left(\times 10^{-3}\right)$ square millimeters per second. 
For all the aforementioned sequences, slice thickness $=$ $3-5 \mathrm{~mm}$ with $1 \mathrm{~mm}$ gap and FOV $=370-400 \mathrm{~mm}$.

Total scanning time was $25 \mathrm{~min}$.

MR images were analyzed by two experienced radiologists in pelvic MR imaging of 25 and 20 years of experience that were not aware of the findings of the ultrasound.

Data collection was done by a radiologist ( 5 years of experience) who is a candidate of medical doctorate.

MR images were analyzed for the following:

a) Increased placental thickness and hypertrophy

b) Signal intensity of the placenta and the presence of focal abnormal signal in the placental tissue: (a) bright signal on T1WI and heterogeneous bright/ bright on T2WI that suggest vascular spaces and (b) heterogeneous bright on T2 and low signal T1WI to locate ischemic areas.

c) Areas of bright signal on T2WI in correlation with focal areas of restriction on the DWI.

d) ADC values measured on the reconstructed ADC maps for the areas of persistent increase of bright signal that was previously located on the DW images.

e) Calculation of the placental volume: Manual tracing of the outline of the placenta was performed in all scanned slices of T2WI sequence (range: 20-58 slices) followed by auto-calculation of the placental volume on an Advantage Workstation (4.1 service) of the used MR devices.

Suggestions for placental insufficiency by the used modalities (3D ultrasound and MR imaging) were correlated with the post partum histopathology of the placenta.

Also, the reference in the assessed placental volume was the post delivery/abortion placental volume.

\section{The statistical methods in establishing the results}

Data were statistically described in terms of mean \pm standard deviation $( \pm \mathrm{SD})$, median and range, or frequencies (number of cases) and percentages when appropriate. Comparison of numerical variables between the study groups was done using Student $t$ test for independent samples, chi-square test, Mann-Whitney test, Wilcoxon signed rank test, Roc curve, and kappa agreement. Accuracy was represented using the terms sensitivity, specificity, and overall accuracy. $P$ values less than 0.05 was considered statistically significant. All statistical calculations were done using computer programs SPSS (Statistical Package for the Social Science; SPSS Inc., Chicago, IL, USA) version 15 for Microsoft Windows.

\section{Results}

The patient's mean age among the case group was $27.9+4.19$, and among the control group was $28.9+$ 5.65. The obstetric code among the included pregnant females was stated in Table 1.

Placental location was a fundal anterior in $65 \%$ of the hypertension case group $(n=26)$ and fundal posterior in $35 \%(n=14)$.

Preeclampsia developed in $17.5 \%(n=7 / 40)$ of the hypertensive pregnant patients and had performed preterm labor.

\section{Doppler findings}

In placental insufficiency, abnormal high RI present either in the right or left uterine artery.

So, we performed a Doppler assessment for the right uterine artery in the cases that showed high RI $(>0.7)$ of the right uterine artery in $75 \%$ of the hypertensive cases, and in the remaining $25 \%$, high RI was noted at the left uterine artery. There was a significant relation between the right uterine artery RI (mean) of both the cases and control groups as $P$ value was 0.014 .

There was a positive correlation between the RI of the right and the left uterine arteries $(P$ value $=0.001)$ and at the same time between the RI of the left uterine artery

Table 1 Obstetric code among groups

\begin{tabular}{|c|c|c|c|c|c|}
\hline & & & Groups & & Total \\
\hline & & & Cases & Controls & \\
\hline Obstetric & G1P0 & Count & 11 & 15 & 26 \\
\hline & & $\%$ within groups & $27.5 \%$ & $37.5 \%$ & $32.5 \%$ \\
\hline & $\mathrm{G} 2 \mathrm{PO}+1$ & Count & 3 & 7 & 10 \\
\hline & & $\%$ within groups & $7.5 \%$ & $17.5 \%$ & $12.5 \%$ \\
\hline & G2P1 & Count & 0 & 1 & 1 \\
\hline & & $\%$ within groups & $.0 \%$ & $2.5 \%$ & $1.25 \%$ \\
\hline & $\mathrm{G} 3 \mathrm{PO}+2$ & Count & 1 & 8 & 9 \\
\hline & & $\%$ within groups & $2.5 \%$ & $20 \%$ & $11.25 \%$ \\
\hline & $\mathrm{G} 3 \mathrm{P} 1+1$ & Count & 3 & 1 & 4 \\
\hline & & $\%$ within groups & $7.5 \%$ & $2.5 \%$ & $5.0 \%$ \\
\hline & G3P2 & Count & 10 & 4 & 14 \\
\hline & & $\%$ within groups & $25.0 \%$ & $10.0 \%$ & $17.5 \%$ \\
\hline & $\mathrm{G} 4 \mathrm{P} 1+2$ & Count & 4 & 1 & 5 \\
\hline & & $\%$ within groups & $10.0 \%$ & $2.5 \%$ & $2.5 \%$ \\
\hline & $\mathrm{G} 4 \mathrm{P} 2+1$ & Count & 2 & 1 & 3 \\
\hline & & $\%$ within groups & $5.0 \%$ & $2.5 \%$ & $3.75 \%$ \\
\hline & G4P3 & Count & 4 & 1 & 5 \\
\hline & & $\%$ within groups & $10.0 \%$ & $2.5 \%$ & $6.25 \%$ \\
\hline & $\mathrm{G} 6 \mathrm{P} 4+1$ & Count & 2 & 1 & 3 \\
\hline & & $\%$ within groups & $5.0 \%$ & $2.5 \%$ & $3.75 \%$ \\
\hline Total & & Count & 40 & 40 & 80 \\
\hline & & $\%$ within groups & $100.0 \%$ & $100.0 \%$ & $100.0 \%$ \\
\hline
\end{tabular}


and the umbilical artery $(P$ value $=<0.001)$ among the group of the hypertensive cases.

The RI values of the uterine arteries and the umbilical artery are documented in Table 2 .

Doppler examination revealed bilateral diastolic notch in both uterine arteries and umbilical artery in about 7.5\% $(n=3 / 40)$ of the hypertensive pregnant females (Fig. 1) and $2.5 \%(n=1 / 40)$ of these cases showed a unilateral notch. None of the control and 90\% $(n=36 / 40)$ of the hypertensive cases showed diastolic notch (Fig. 2). There was a positive correlation between the presence of diastolic notch and the RI value as the calculated $P$ value was significant (0.012).

\section{Findings at the MRI examination of the placenta}

Qualitative assessment of T2 and diffusion-weighted images was demonstrated in Table 3.

About 15\% of the hypertensive pregnant females had focal abnormal areas in their placenta of heterogeneous bright $\mathrm{T} 2$ signal.

In the diffusion-weighted images, 30\% of the hypertensive cases showed areas of restricted diffusion (presumed infarction) in the placenta (Fig. 1).

There was a positive correlation and a significant relation between the positive findings of ischemia in the T2-weighted and diffusion-weighted images among the hypertensive pregnant females as the $P$ value was significant (0.002). Also, there was a significant difference between patients with the normal placenta and those showed abnormal placental signal in the diffusion images as $P$ value was significant (0.047) (Figs. 1 and 3). These data may suggest that diffusion-weighted imaging of the placenta is very useful for detection of ischemic changes in pregnant hypertensive patients.

ADC maps were performed and we measured of the $\mathrm{ADC}$ values for the abnormal focal areas of restricted diffusion in the hypertensive cases as well as the normalappearing placental tissue in both the hypertensive cases and the control.

The mean ADC value in the control was $1.87 \times 10^{-3} \mathrm{~mm}^{2} / \mathrm{s}$.

The mean ADC value plotted for the normal placental tissue in the hypertensive cases was $1.81 \times 10^{-3} \mathrm{~mm}^{2} / \mathrm{s}$ versus $1.36 \times 10^{-3} \mathrm{~mm}^{2} / \mathrm{s}$ in the focal areas of ischemic changes (i.e., infractions).

We found that there was a significant correlation between the mean ADC value of both the hypertensive cases and the control $(P$ value $=0.040)$ and between the mean ADC value among hypertensive cases with normal placentae and those with placental ischemic changes $(P$ value $=<0.001$ ).

ROC curve for the placental ischemia was significantly different $(P=<0.001)$ between the studied groups. The area under the curve (AUC) distinguished between the hypertensive cases and the control. AUC of the hypertensive pregnant cases was significantly high $(1.00=100 \%)$. A cut-off ADC value of $1.46 \times 10^{-3} \mathrm{~mm}^{2} / \mathrm{s}$

Table 2 Analysis of the Rl of the right, the left uterine, and the umbilical arteries in the included cases

\begin{tabular}{|c|c|c|c|c|c|c|}
\hline Groups & & & Age & Right uterine artery RI & Left uterine artery RI & Umbilical artery Rl \\
\hline \multirow[t]{9}{*}{ Hypertensive cases } & $N$ & Valid & 40.00 & 40.00 & 40.00 & 40.00 \\
\hline & & Missing & .00 & .00 & .00 & .00 \\
\hline & Mean & & 27.90 & .60 & .60 & .68 \\
\hline & Std. deviation & & 4.19 & .08 & .07 & .09 \\
\hline & Minimum & & 18.00 & .46 & .42 & .49 \\
\hline & Maximum & & 35.00 & .81 & .82 & .98 \\
\hline & Percentiles & 1st quartile & 25.00 & .56 & .58 & .63 \\
\hline & & Median & 27.50 & .59 & .60 & .66 \\
\hline & & 3rd quartile & 31.75 & .63 & .62 & .70 \\
\hline \multirow[t]{9}{*}{ Control cases } & $N$ & Valid & 40.00 & 40.00 & 40.00 & 40.00 \\
\hline & & Missing & .00 & .00 & .00 & .00 \\
\hline & Mean & & 28.90 & .53 & .59 & .68 \\
\hline & Std. deviation & & 5.65 & .08 & .04 & .05 \\
\hline & Minimum & & 19.00 & .34 & .51 & .61 \\
\hline & Maximum & & 38.00 & .62 & .67 & .77 \\
\hline & Percentiles & 1st quartile & 24.25 & .48 & .56 & .63 \\
\hline & & Median & 31.00 & .56 & .60 & .68 \\
\hline & & 3rd quartile & 32.00 & .60 & .61 & .72 \\
\hline
\end{tabular}




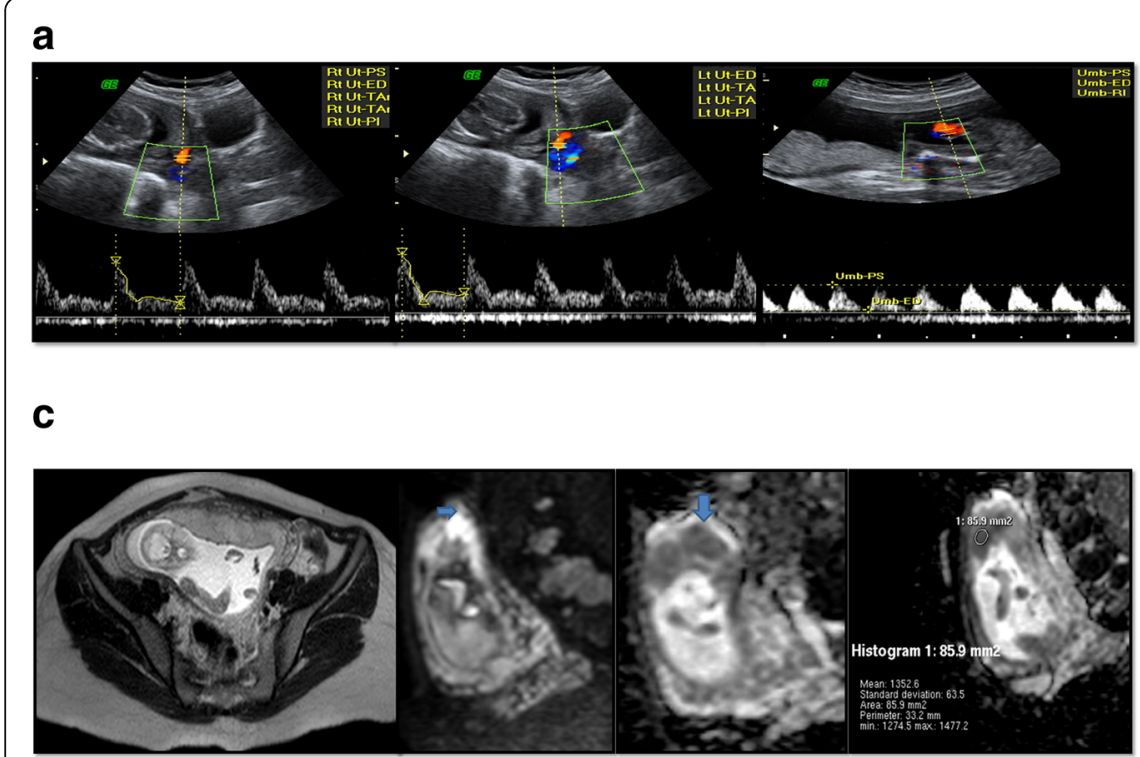

b

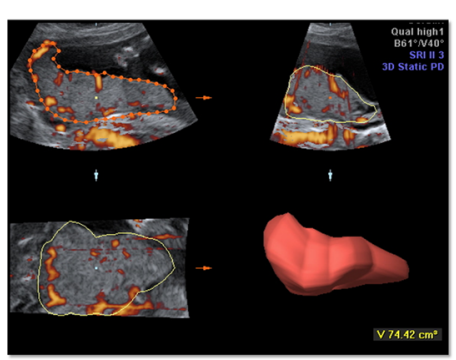

d

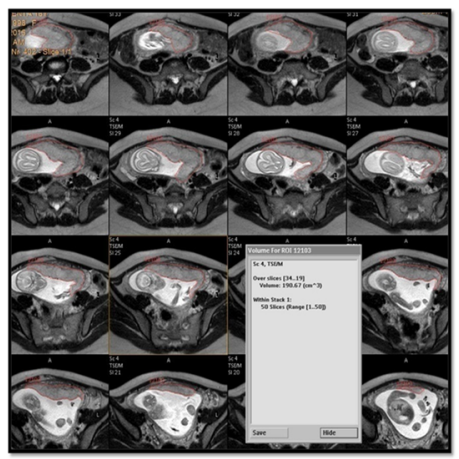

Fig. 1 Pregnant female, 18 years old. The patient has hypertension with pregnancy on Aldomet and Aspocid. Her obstetric code was G1P0. The patient did not remember her 1st day of LMP by ultrasound, and her gestational age was 22 weeks +1 day. a Doppler examination of both uterine arteries showed bilateral diastolic notches with RI of the right uterine artery 0.7 and the left uterine artery 0.69. Doppler of the umbilical artery showed RI 0.91. b 3D ultrasound measured the volume of the placenta $\left(74.42 \mathrm{~cm}^{3}\right.$ ). c From the right to left, (i) axial T2-weighted image showed a heterogeneous low signal of the placenta, (ii) sagittal DWI at b 850, and (iii) ADC map: bright signal in DWI and low signal in ADC map (arrows) and low ADC value (1.35) suggestive of placental infarctions. d Placental volume measurement by MRI $\left(190.67 \mathrm{~cm}^{3}\right)$. Comments: The patient had gestational hypertension. Both 3D ultrasound and MR showed features of placental insufficiency and small volume. The patient developed preeclampsia and had preterm labor

achieved a sensitivity of $91 \%$ and specificity of $100 \%$. Sensitivity value increased to $100 \%$ when a mean ADC value of $1.59 \times 10^{-3} \mathrm{~mm}^{2} / \mathrm{s}$ was used.

There was a significant agreement between the results of both the 3D US and the diffusion-weighed imaging in the hypertensive pregnant cases group as $P$ value was 0.006 and kappa value was 0.318 (Table 4).

Measurement of the placental volume in the hypertensive pregnant females

\section{Placental volume among hypertensive patients by both}

\section{modalities}

The mean placental volume by US $=374.11+251.52$ with median (IQR) 329.02 (162.66-596.75).

The mean of placental volume by $\mathrm{MRI}=500.5+$ 223.12 with median (IQR) 507.08 (311.22-721.85).

\section{Placental volume among the control groups by both modalities}

The mean of placental volume by MRI $=574.23+259.29$ with median (IQR) 646.21 (321.54-808.37).

The mean of placental volume by US $=444.22+285.08$ with median (IQR) 329.93 (210.81-729.38).
The sensitivity, specificity, and accuracy of the 3D ultrasound were $73 \%, 91 \%$, and $99 \%$, while the MR imaging supported by the DWI were $100 \%, 99 \%$, and $99 \%$, respectively, in their ability to assess ischemic changes of the placentae and predict placental insufficiency in cases of gestational hypertension.

There was a positive correlation between the measurement of the placental volume by both US and MRI as $P$ value was significant $(<0.001)$ and $(0.008)$, respectively.

\section{Discussion}

The most dangerous situation any female could experience during pregnancy is the preeclampsia syndrome whether it presents as an individual symptom or as newly developed on top of chronic hypertension [7].

For many years, ultrasound aided with the Doppler study is the first and sometimes the sole method of evaluation of the placenta. To date, pathologies of the placenta have not been considered a routine indication of MR imaging [8].

Our study included 80 pregnant women, 40 of them presented with gestational hypertension but not diagnosed of preeclampsia yet and another 40 cases were control ones who were free from any 

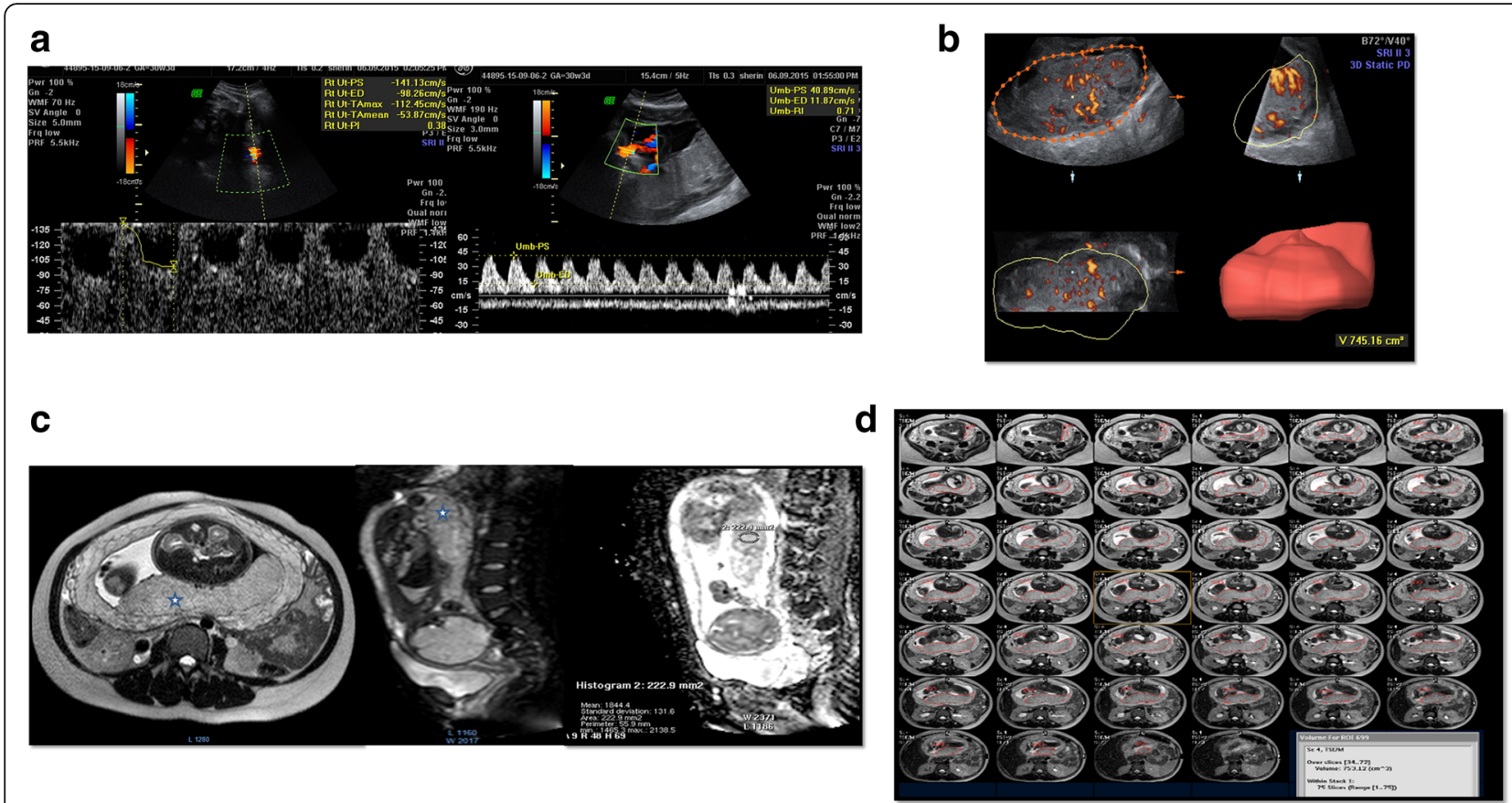

Fig. 2 Pregnant female, 19 years old. She did not have any medical problems with her pregnancy. Her obstetric code was G1P0. Gestational age: 30 weeks +3 days. a Doppler examination of the uterine and umbilical arteries showed normal RI. $\mathbf{b}$ Volume assessment of the placenta by 3D ultrasound: $745.16 \mathrm{~cm}^{3}$.c From right to left, (i) axial T2-weighted image, (ii) sagittal DWI at b 850, and (iii) ADC map that showed average thickness and homogenous texture of the placenta with no abnormal signal noted. ADC value equals $1.84 \times 10-3 \mathrm{~mm}^{2} / \mathrm{s}$. d Volume measurement of the placenta by MRI $\left(752.12 \mathrm{~cm}^{3}\right)$. Comments: Both 3D ultrasound and MR showed normal findings and comparable volume measurement of the placenta. She had normal vaginal delivery and average-weighted viable fetus

medical disorders by history and clinical examination.

The patient's mean age among the case group was $27.9+4.19$ and among the control group was $28.9+5.65$. Both groups were examined between 22 and 34 weeks of gestation by both 3D ultrasound and MRI examinations with a time interval of 7 days between both examinations.

In this study, we evaluated placental function in the second-trimester pregnancy in view of (1) assessment of

Table 3 Demonstrated MR findings at T2- and diffusion-weighted imaging in the included hypertensive pregnant patients

\begin{tabular}{|c|c|c|c|c|}
\hline \multirow[t]{2}{*}{ Diffusion-weighted images } & & \multicolumn{2}{|l|}{ Groups } & \multirow[t]{2}{*}{ Total } \\
\hline & & Cases & Controls & \\
\hline \multirow[t]{2}{*}{ Normal signal } & Count & 28 & 40 & 68 \\
\hline & $\%$ within groups & $70.0 \%$ & $100.0 \%$ & $85.0 \%$ \\
\hline \multirow[t]{2}{*}{ Restriction (infarction = count ischemic changes) } & Count & 12 & 0 & 12 \\
\hline & $\%$ within groups & $30.0 \%$ & $.0 \%$ & $15.0 \%$ \\
\hline \multirow[t]{2}{*}{ Total } & Count & 40 & 40 & 80 \\
\hline & $\%$ within groups & $100.0 \%$ & $100.0 \%$ & $100.0 \%$ \\
\hline \multirow[t]{2}{*}{ T2-weighted images } & & Groups & & Total \\
\hline & & Cases & Controls & \\
\hline \multirow[t]{2}{*}{ Normal signal } & Count & 32 & 32 & 64 \\
\hline & $\%$ within groups & $80.0 \%$ & $80.0 \%$ & $80.0 \%$ \\
\hline \multirow[t]{2}{*}{ Abnormal signal } & Count & 8 & 8 & 16 \\
\hline & $\%$ within groups & $20.0 \%$ & $20.0 \%$ & $20.0 \%$ \\
\hline \multirow[t]{2}{*}{ Total } & Count & 40 & 40 & 80 \\
\hline & $\%$ within groups & $100.0 \%$ & $100.0 \%$ & $100.0 \%$ \\
\hline
\end{tabular}


a

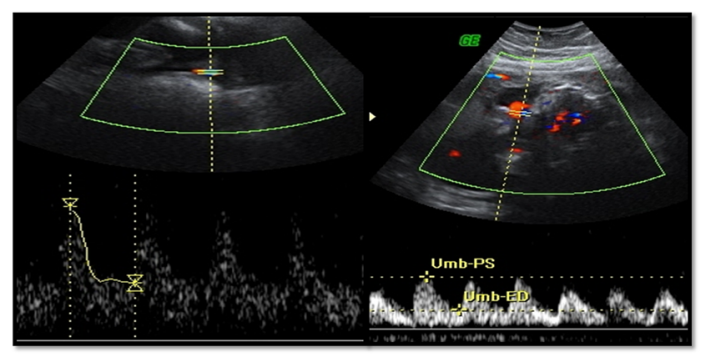

b

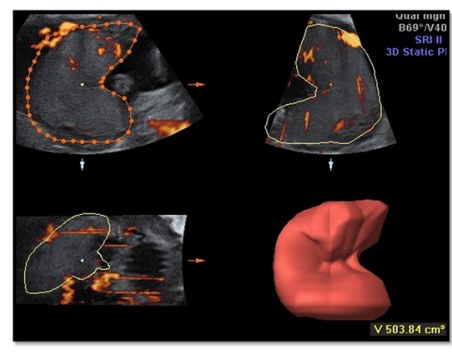

C

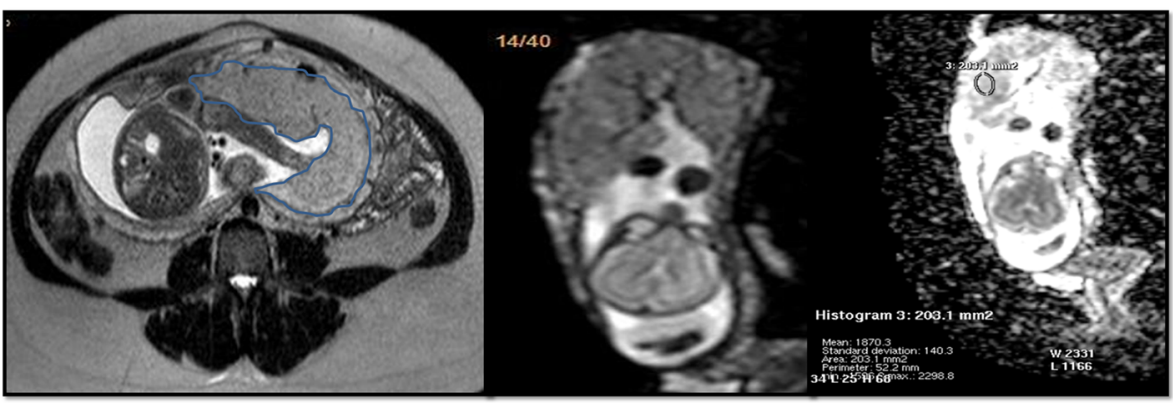

d

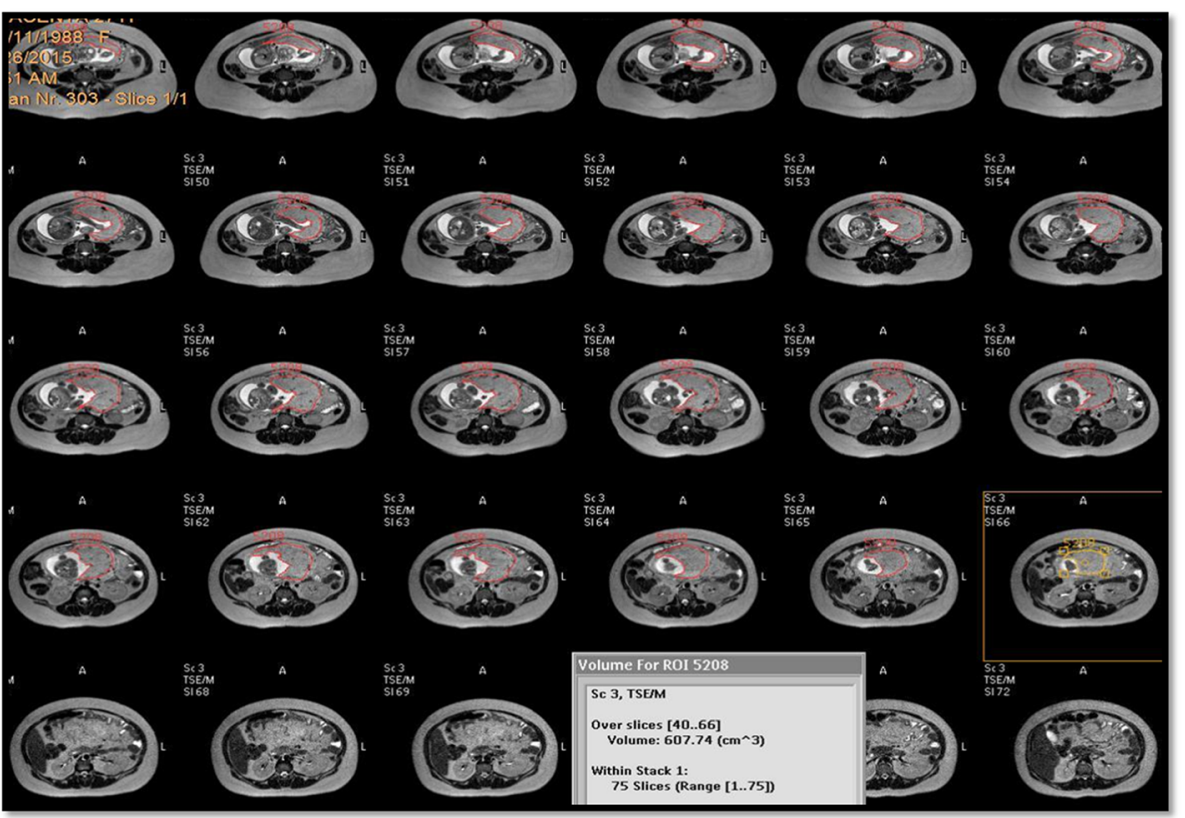

Fig. 3 Pregnant female, 27 years old. The patient has hypertension with pregnancy on Aldomet. No history of preeclampsia. Her obstetric code was G4P1 + 2. Gestational age: 25 weeks + 5 days. a Doppler examination of both uterine and umbilical arteries showed normal Rl of the examined arteries, a normal wave of the uterine artery, and no notch. b Placental volume measurement by 3D ultrasound $\left(503.84 \mathrm{~cm}^{3}\right) . \mathbf{c ~ F r o m ~}$ right to left, (i) axial T2-weighted image, (ii) sagittal DWI at b 850, and (iii) ADC map that showed average placenta thickness and normal homogenous pattern. ADC value equals $1.87 \times 10-3 \mathrm{~mm}^{2} / \mathrm{s}$. d Placental volume measurement by MRI $\left(607.74 \mathrm{~cm}^{3}\right)$. Comments: The patient had gestational hypertension but 3D ultrasound and MR showed features of a normal placenta. MRI was more accurate in the assessment of the placental volume. She had a cesarean section with normal averaged weight fetus

the uterine and the umbilical arteries by Doppler ultrasound. (2) Evaluation of the signal intensity of the placenta by diffusion MR imaging and measuring the ADC values of the focal areas of abnormal signal.
(3) Measuring placental volume by MRI and 3D ultrasound.

During our analysis, we agreed with Derwig et al. [9] who stated that uterine artery resistance index (RI) value 
Table 4 Diffusion in correlation with ultrasound in hypertensive cases

\begin{tabular}{|c|c|c|c|c|c|c|}
\hline & & & Ultrasound & & & Total \\
\hline & & & Negative cases & Positive cases & & \\
\hline Diffusion & Negative & Count & 28 & 0 & & 28 \\
\hline & & $\%$ within US findings & $75.7 \%$ & $0.0 \%$ & & $70.0 \%$ \\
\hline & Positive & Count & 9 & 3 & & 12 \\
\hline & & $\%$ within US findings & $24.3 \%$ & $100.0 \%$ & & $30.0 \%$ \\
\hline Total & & Count & 37 & 3 & & 40 \\
\hline & & $\%$ within US findings & $100.0 \%$ & $100.0 \%$ & & $100.0 \%$ \\
\hline Chi-squar & & & & & & \\
\hline & & Value & $d f$ & Asymp. Sig. (two-sided) & Exact Sig. (two-sided) & Exact Sig. (one-sided) \\
\hline Pearson c & & $7.568^{b}$ & 1 & 0.006 & & \\
\hline Continuit & ction $^{\mathrm{a}}$ & 4.393 & 1 & 0.036 & & \\
\hline Likelihoo & & 7.815 & 1 & 0.005 & & \\
\hline Fisher's e & & & & & 0.022 & 0.022 \\
\hline Linear-by & association & 7.738 & 1 & 0.007 & & \\
\hline$N$ of valid & & 40 & & & & \\
\hline Symmetri & sures & & & & & \\
\hline & & Value & Asymp. Std. erro & & Approx. $T^{\mathrm{b}}$ & Approx. Sig. \\
\hline Measure & ement kappa & 0.318 & 0.146 & & 2.751 & 0.006 \\
\hline$N$ of valid & & 40 & & & & \\
\hline
\end{tabular}

was a useful diagnostic tool in assessment of vascular abnormalities in hypertensive pregnancies (Fig. 1) as we found a significant relation ( $P$ value 0.014 ) between the right uterine artery RI (mean) of both the hypertensive cases and the control. We performed Doppler examination of the uterine artery where $7.5 \%$ of the included hypertensive patients showed bilateral diastolic notch and elevated RI of both the uterine arteries while the remaining $2.5 \%$ had a unilateral notch and elevated RI was noticed in the left uterine artery. The aforementioned findings are important criteria in the assessment of hypertensive patients with suspected placental insufficiency as was justified by the positive correlation (significant $P$ value of 0.012 ) that was detected between the presence of diastolic notch and RI value.

Our results matched with Coleman et al. [10], they reported that the higher RI cut-off value $(\geq 0.7)$ or the presence of notching at the Doppler test enabled to identify pregnant women at high risk of placental insufficiency.

The presence of a diastolic notch was reported to be a better predictor of pre-eclampsia than an elevated RI or systolic/diastolic ratio, with positive predictive values up to $31 \%[10]$.

In the current work, when we performed the qualitative assessment for the MR imaging of the placenta, abnormal heterogeneous bright signal was noted in the T2WIs that was corresponded to areas of restricted diffusion in the diffusion-weighted images in $15 \%$ of the included hypertensive pregnant cases. Such areas represented placental ischemic changes. These findings agreed with those of Himoto et al. [11] who reported that placentae with impaired function show decreased signal compared to normal placentas. They also explained that the degree of low signal might depend on the decrease of placental circulation and the degree of compensatory alteration.

Derwig et al. [9] reported that T2 relaxation of the placenta during the second trimester is shorter in hypertensive pregnancies and that it correlates with our findings.

In DWI, areas of necrosis, infarction, or fibrosis that may be seen in the insufficient placenta result in altered diffusion [12]. Also, such sequence can be used to create an apparent diffusion coefficient (ADC) map that identifies and quantifies areas of accelerated and restricted diffusion. Therefore, in the pathologic placenta, DWI and ADC mapping had the potential to quantify early changes in diffusion even in the absence of abnormal findings on US/conventional MRI [12].

Our work showed a significant difference between patients with normal and those with an abnormal placental signal in the diffusion-weighted images $(P=0.047)$.

In diffusion-weighted images, our study showed that $30 \%$ of the hypertensive patients displayed areas of restricted diffusion (in the form of persistent bright signal) in their placenta, compared to only $15 \%$ seen on the T2WI sequence as mentioned earlier. 
There were a positive correlation and a significant relationship between the T2WI and the DWI among the included hypertensive pregnant females $(P=0.002)$.

We noticed that measured ADC values of the placental parenchyma were significantly lower in the placentae with ischemic changes in the hypertensive pregnant cases when compared with those of normal pregnancies. The mean ADC value in the control was $(1.87 \pm 0.26$ $\mathrm{mm}^{2} / \mathrm{s}$ ) while in patients with placental ischemic changes, the mean ADC value was $\left(1.36 \pm 0.09 \mathrm{~mm}^{2} / \mathrm{s}\right)$.

Our results agreed with other studies as Siauve et al. [13] who reported that ADC value was significantly lower in placentae of fetuses with growth retardation when compared with normal ones. They stated that the most promising parameters appear to be the mean ADC value in the placenta which was in normal pregnancywhich according to them $-1.77 \pm 0.19 \times 10^{-3} \mathrm{~mm}^{2} / \mathrm{s}$, while in placentas with insufficient function, the mean $\mathrm{ADC}$ value was decreased, $1.46 \pm 0.1 \times 10-3 \mathrm{~mm}^{2} / \mathrm{s}$.

Also, Manganaro et al. [14] studied fetal MRIs of 145 pregnant women with gestational age range 19-40 weeks. ADC values calculated on the DWI images obtained had a range from 1 to $2.4 \times 10^{-3} \mathrm{~mm}^{2} / \mathrm{s}$.

In our analysis, the area under the curve (AUC) of the hypertensive patients was significantly high $(1.00=100 \%)$. The maximum sensitivity and specificity was achieved (sensitivity $91 \%$ and specificity $100 \%$ ) with ADC value of $1.46 \times 10^{-3} \mathrm{~mm}^{2} / \mathrm{s}$. A higher sensitivity of $100 \%$ was noted with a mean ADC value of $1.59 \times 10^{-3} \mathrm{~mm}^{2} / \mathrm{s}$.

A retrospective study of DW imaging of the placenta in growth-restricted and non-growth restricted fetuses showed low measurements of ADC values of the placenta in the growth-restricted fetuses [12]. In our work, the addition of DWI to the 3D ultrasound assessment of the placenta showed increased sensitivity to detect placental insufficiency from 73 to $100 \%$, increased accuracy of diagnosis from 91 to $99 \%$, and sustained specificity of $99 \%$.

We found significant agreement between the results of both 3D US with Doppler application and DW MR imaging in hypertensive pregnant cases as $P$ value was significant (0.006) and kappa value was 0.318 .

Our results agreed with Bonel et al. [15] which stated that Doppler US may be insensitive to detect early placental dysfunction. Also, Messerschmidt et al. [8] mentioned that a significant placental vascular disease that remains below the threshold of detection by Doppler assessment of the uterine and umbilical arteries can be predicted by MR imaging.

It is impossible to image the whole placenta by ultrasound which interferes in the accurate measurements of placental size. The measurement by ultrasound is likely to be affected by maternal habitus, amniotic fluid volume, fetal position, multiple gestation, and gestational age. In contrast, MRI has a wide field of view and is not affected by variables as amniotic fluid volume or maternal habitus [16].
Several investigators were concerned about measuring the placental volume using 3D ultrasound to predict infants who could be small for gestational age [17-19]. Also, for the same purpose, the placental volume was assessed by MRI [16]. These studies concluded that pregnancies complicated by fetal growth restriction are associated with placental insufficiency and reduced placental volume.

To our knowledge, the measurement of the placental volume by 3D US and MR has not been used before to assess the risk of placental insufficiency.

In our study, MR imaging presented more accurate measurements of the placental volume than ultrasound in 70 patients $(87.5 \%)$. We measured the surface area of the placenta in each taken slice, and with the aid of advanced workstation, we calculated the total placental volume. We found a positive correlation between the measurements of placental volume by both 3D US and MRI in the control and hypertensive cases, respectively. The MRI values were the ones closer to the post delivery real placental volume (Figs. 1 and 3). There was a significant difference between the measurements of the placental volume by both modalities as $P$ values were 0.001 and 0.017 , respectively.

In our study, diffusion MR imaging revealed that 30\% had placental ischemic changes $(n=12 / 40)$ and out of them, $17.5 \%$ developed preeclampsia $(n=7)$ and preterm labor. This could be attributed to the different clinical condition of each patient, the medical treatment received, and the capability of the fetoplacental unit to compensate.

Again, here, we agreed with Bonel et al. [15] who reported that DWI showed signs of placental ischemia not obtained with US. However, one must be aware that not all abnormalities detected at diffusionweighted imaging indicate growth restriction; it is possible that the fetoplacental unit will partially compensate for placental insufficiency.

The strength of the study was the inclusion of pregnant patients with a high level of adverse outcome, especially that gestational hypertension is uncommon representative of the obstetric population.

\section{Conclusion}

Diffusion-weighted MR imaging and 3D ultrasound both can be used individually or in combination as screening tests for placental insufficiency that may accompany pregnancy conditions with induced hypertension. Moreover, DWI can detect early changes and signs of placental insufficiency supported by the wide field of view and multislice scanning required for accurate measurement of the placental volume.

\section{Abbreviations}

2DUS: Tw-dimensional ultrasound; 3DUS: Three-dimensional ultrasound; ADC: Apparent diffusion coefficient; AUC: Area under the curve; 
DWI: Diffusion-weighted imaging/diffusion MR imaging; FOV: Field of view; IQR: Interquartile range; IUFD: Intra-uterine fetal death; MRI: Magnetic resonance imaging; PI: Pulsatility index; RI: Resistance index; ROC: Receiver operating characteristic; ROI: Region of interest; SD: Standard deviation; SE: Spin echo; SPSS: Statistical Package for the Social Science; T1-TFE: T1turbo fast echo; T1WI: T1-weighted image; T2WI: T2-weighted image; TE: Time of echo; TR: Time of repetition; US: Ultrasound; VOCAL: Virtual organ computer-aided analysis

\section{Acknowledgements}

We would like to acknowledge the head of our unit Dr. Rasha Kamal who helped us through this work.

\section{Authors' contributions}

HTS is the guarantor of integrity of the entire study. HTS and MS contributed to the study concepts and design. MS, HS, and SS contributed to the literature research. MS, HS, and SS contributed to the clinical studies. MS and SS contributed to the experimental studies/data analysis. MS and SS contributed to the statistical analysis. MS, HS, and SS contributed to the manuscript preparation. MS, HS, and SS contributed to the manuscript editing. All authors have read and approved the final manuscript.

\section{Funding}

No source of funding.

\section{Availability of data and materials}

The corresponding author is responsible for sending the used data and materials upon request.

\section{Ethics approval and consent to participate}

The study was approved by the ethical committee of the Obstetrics and Gynecology and the Radiology Departments of an academic highly specialized multidisciplinary hospital, and an informed written consent was taken from all the control and case groups of patients that were included in the study.

The ethics committee's reference number is not applicable.

\section{Consent for publication}

All authors approved the manuscript. All patients included in this research were legible, above 16 years of age. They gave written informed consent to publish the data contained within this study.

\section{Competing interests}

The authors declare that they have no competing interests.

\section{Author details}

${ }^{1}$ Radiology Department (Women's Imaging Unit), Faculty of Medicine, Kasr ElAiny Hospital, Cairo University, Cairo, Egypt. ºbstetrics and Gynecology, Department Faculty of Medicine, Kasr Al-Ainy Hospital, Cairo University, El-Manial, Cairo 11956, Egypt.

Received: 20 September 2019 Accepted: 1 October 2019

Published online: 18 November 2019

\section{References}

1. Gagnon R (2003) Placental insufficiency and its consequences. Eur J Obstet Gynecol Reprod Biol 110:99-107

2. Steegers EA, von Dadelszen P, Duvekot JJ, Pijnenborg R (2010) Preeclampsia. Lancet. 376:44-631

3. Masseli G, Gualdi G (2013) MR imaging of the placenta: what a radiologist should know. Abdominal imaging 38:573-578

4. Hafner E, Metzenbauer M, Dillinger-Paller B, Hoefinger D, Schuchter K et al (2001) Correlation of first trimester placental volume and second trimester uterine artery Doppler flow. Placenta. 22:729-734

5. Ghosh GS, Gudmundsson S (2009) Uterine and umbilical artery Doppler are comparable in predicting perinatal outcome of growth-restricted fetuses. Int J Obst Gynecol 116:424-430

6. Kubik-Huch RA, Wildermuth S, Cettuzzi L, Rake A, Seifer B et al (2001) Fetus and uteroplacental unit: fast MR imaging with three-dimensional reconstruction and volumetry-feasibility study. Radiology. 219:567-573
7. Cunningham FG, Leveno KJ, Bloom SL, Hauth JC, Rouse DJ et al (2010) Pregnancy hypertension. In: Williams Obstetrics: 23rd ed. States: The McGraw-Hill Companies

8. Messerschmidt A, Baschat A, Linduska N, Kasprian G, Brugger C et al (2011) Magnetic resonance imaging of the placenta identifies placental vascular abnormalities independently of Doppler ultrasound. Ultrasound Obstet Gynecol 37:717-722

9. Derwig I, Barker GJ, Poon L, Zelaya F, Gowland P et al (2013) Association of placental T2 relaxation times and uterine artery Doppler ultrasound measures of placental blood flow. Placenta. 34:474-479

10. Coleman MAG, McCowan LME, North RA (2000) Mid-trimester uterine artery Doppler screening as a predictor of adverse pregnancy outcome in highrisk women. Ultrasound Obstet Gynecol 15:7-12

11. Himoto Y, Kido A, Mogami H, Moribata Y, Minamiquchi S et al (2016) Placental function assessed visually using half-Fourier acquisition single-shot turbo spin echo (HASTE) magnetic resonance imaging. Placenta. 39:55-60

12. Andescavage NN, Du Plessis A, Limperopoulos C (2015) Advanced MR imaging of the placenta: exploring the in utero placenta-brain connection. MR Imaging of the Developing Brain 34:113-123

13. Siauve N, Chalouhi GE, Deloison B, Alison M, Clement O et al (2015) Functional imaging of the human placenta with magnetic resonance. Am J Obst Gynecol 213:103-114

14. Manganaro L, Fierro F, Tomei A, La Barbera L, Savelli S, Sollazzo P et al (2010) MRI and DWI: feasibility of DWI and ADC maps in the evaluation of placental changes during gestation. Prenat Diagn 30(12-13):1178-1184

15. Bonel HM, Stolz B, Diedrichsen L, Frei K, Saar B, Tutschek B et al (2010) Diffusion-weighted MR imaging of the placenta in fetuses with placental insufficiency. Radiology. 257:810-819

16. Derwig IE, Akolekar R, Zelaya FO, Gowland PA, Barker GJ, Nicolaides KH (2011) Association of placental volume measured by MRI and birth weight percentile. J Magn Reson Imaging 34(5):1125-1130

17. Thame M, Osmond C, Wilks RJ, Bennett Fl, Forrester TE (2001) Second trimester placental volume and infant size at birth. Obstet Gynecol 98:279-283

18. Artunc-Ülkümen B, Pala HG, Uyar Y, Baytur YB (2014) The alteration in placental volume and placental mean grey value in growth-restricted pregnancies assessed by 3D ultrasound (growth restriction \& 3D ultrasonography). J Obstet Gynaecol 35(5):1-4

19. Abulé RMD, Bernardes LS, Doro GF, Miyadahira S, Francisco RPV (2016) Reduced placental volume and flow in severe growth restricted fetuses. Clinics. 71(6):332-337

\section{Publisher's Note}

Springer Nature remains neutral with regard to jurisdictional claims in published maps and institutional affiliations.

\section{Submit your manuscript to a SpringerOpen ${ }^{\bullet}$ journal and benefit from:}

- Convenient online submission

- Rigorous peer review

- Open access: articles freely available online

- High visibility within the field

Retaining the copyright to your article

Submit your next manuscript at $>$ springeropen.com 